\title{
MICTURITION PATTERNS IN PATIENTS PARAPLEGIC FOLLOWING SPINAL CORD INJURY
}

\author{
By P. H. SMith, M.B., F.R.C.S. and J. B. Cook, M.D., F.R.C.P. \\ Leeds Regional Spinal Injuries Unit, Pinderfields General Hospital, Wakefield
}

\section{Introduction}

MANAGEMENT of the bladder following complete and incomplete spinal cord injury is directed towards obtaining a satisfactory flow of urine with a low residual urine as soon as possible and whether or not the patient develops any awareness of bladder fullness. This process is often referred to as bladder training. The methods generally adopted to initiate and to maintain urine flow in patients with an intact sacral cord include various manoeuvres designed to stimulate the bladder reflex such as pinching the skin over the abdomen, scratching the scrotum or thumping with the fist in the suprapubic region. Bladder emptying can sometimes be assisted by inserting a finger into the rectum and pulling backwards, a technique which relaxes the muscles of the pelvic floor. In patients with a flaccid bladder voiding may be initiated and maintained by straining or by manual suprapubic pressure. The patient is encouraged to use whatever method he finds most satisfactory and it is important that he should make every effort to empty the bladder completely.

The object of this investigation was to record the patterns of micturition in such patients months or years after the time of their injury.

\section{Apparatus and Method}

Measurement of the rate of flow of urine and of the total volume of urine voided was made with a Disa type I4 F 45 mictiograph which contained a $\mathrm{I}_{4} \mathrm{~F} 42$ uroflow transducer and a type I4 F 45 uroflow graph. Recordings were made of three normal male subjects and of I8 male patients, paralysed after spinal cord injury, whose urinary tracts were known to be satisfactory and who were considered to have established a reasonable pattern of bladder management.

The patients, wearing condom urinals, were encouraged to drink two litres of water over a two-hour period and to lift themselves in their wheelchairs every Io to I5 minutes to encourage urine flow. After the patients had drunk all the water the condom urinal was removed and the patient was asked to void directly into the mictiograph. Tracings of the flow of urine and of the volume voided were made after which the residual urine was determined by urethral catheterisation. The patient pressed a signal button when he was about to void and again at the end of micturition. The control subjects passed urine into the mictiograph at a convenient time. 


\section{Results}

The normal subjects showed hesitancy of only one to two seconds, a rapid rise in flow rate to $20-25 \mathrm{mls}$./second and a sustained flow for $20-30$ seconds during which most of the urine was voided. Each trace also had a terminal segment lasting 5-10 seconds in which the last few mls. were passed, after which micturition ceased. A typical normal trace is shown in Figure $I$ and a trace from a patient with bladder neck obstruction in Figure 2.
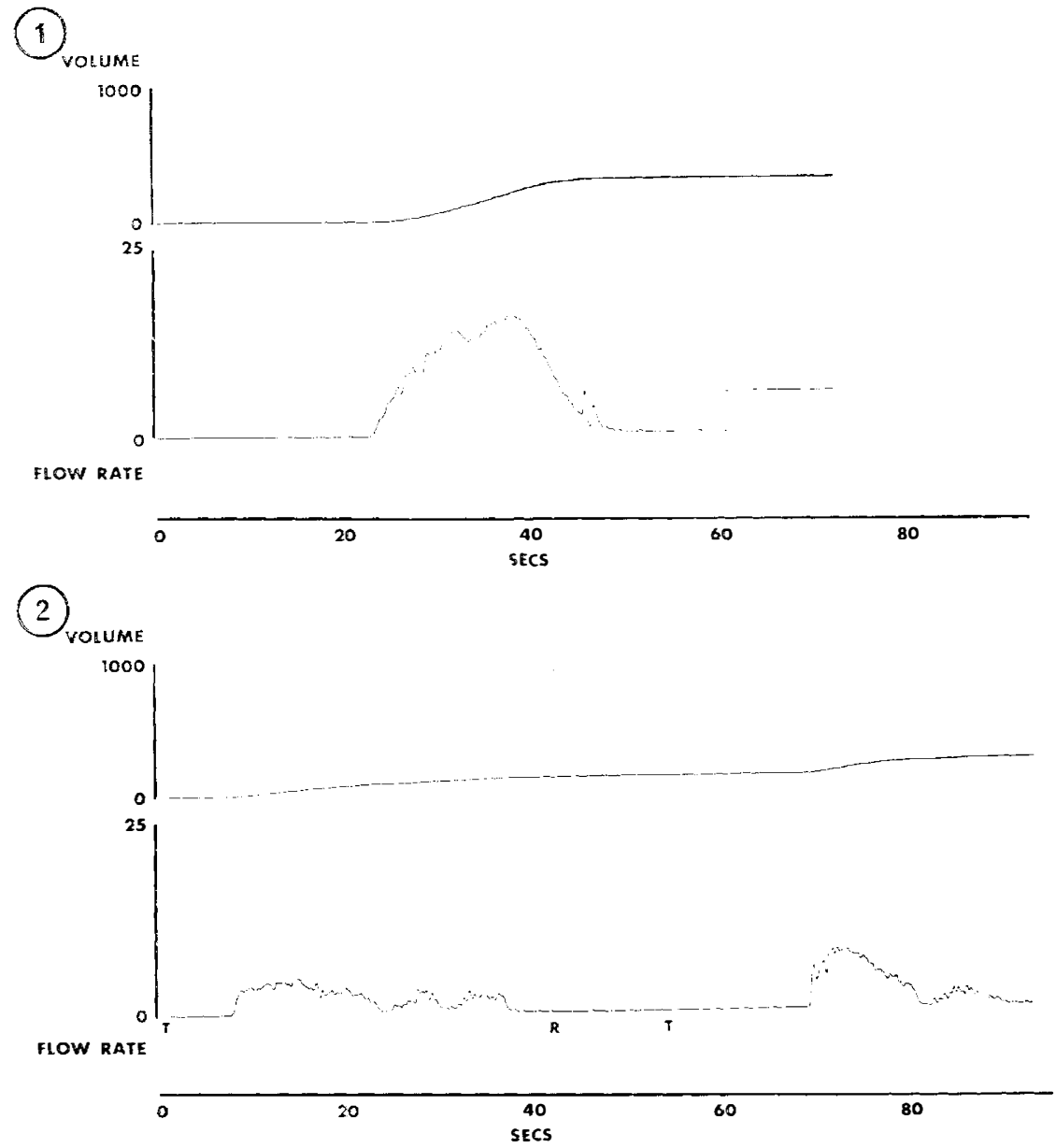

FIG. I

Trace of urine flow rate in normal male.

FIG. 2

Trace of urine flow rate in patient with bladder neck obstruction. (T-start of attempt to pass urine by tapping the lower abdomen, $\mathrm{R}$-rest). 
Of the patients studied, six had complete lesions of the spinal cord (Table I) and seven had incomplete lesions (Table II). A further five patients with complete lesions were investigated following transurethral resection of bladder neck and external sphincter (Table III). Figures 3 and 4 show samples of the traces in each group. It can be seen from the specimen tracings in Figures 3 and 4 that

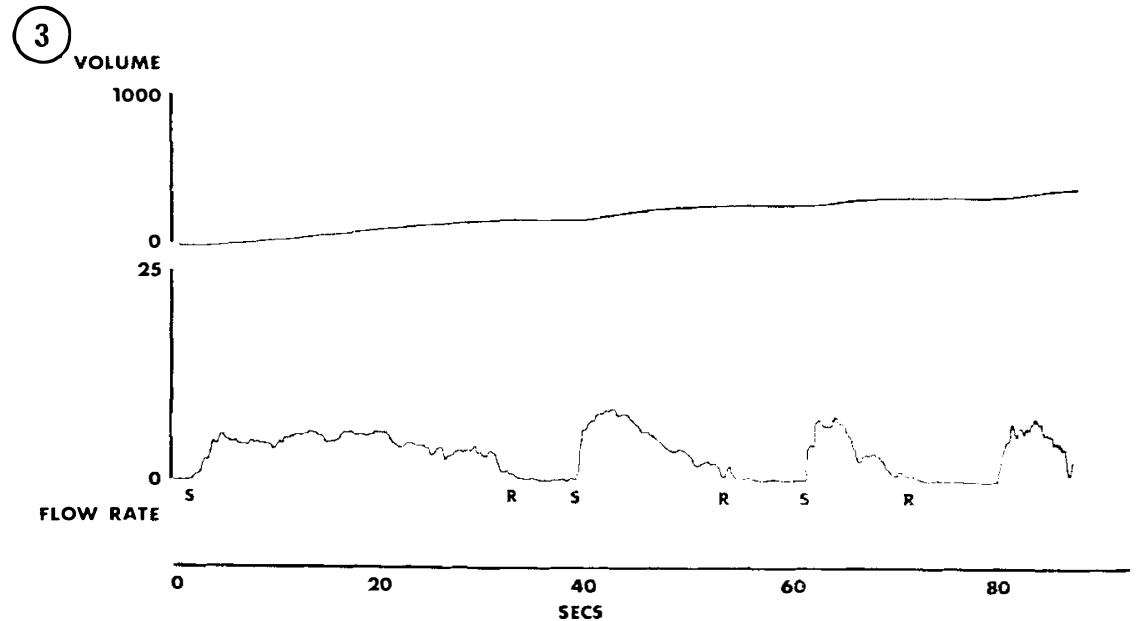

(4)

4 volume
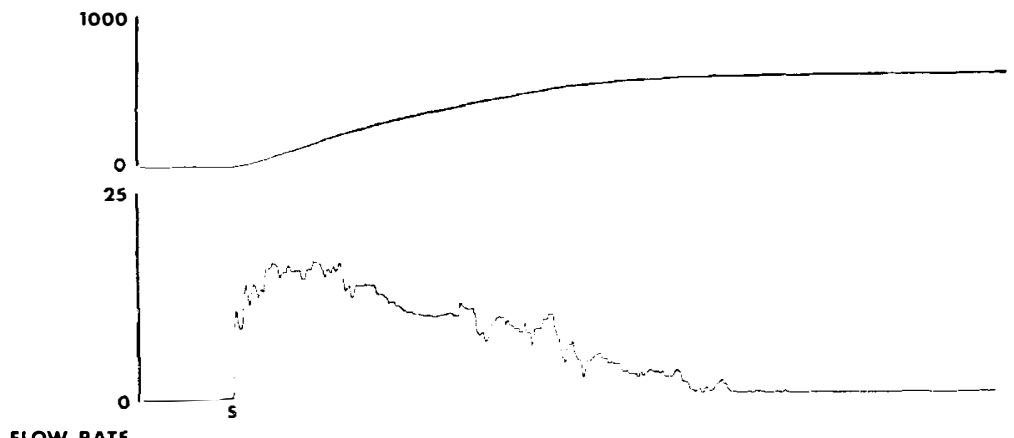

FLOW RATE

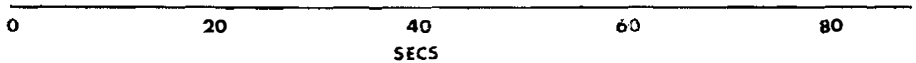

FIG. 3

Trace of urine flow in patient following spinal cord injury showing passage of urine in small amounts on straining. ( $\mathrm{S}$-commencement of straining, $\mathrm{R}$-resting.)

FIG. 4

Trace of urine flow rate in paraplegic patient following transurethral resection of bladder neck and external sphincter. (S-straining.) 

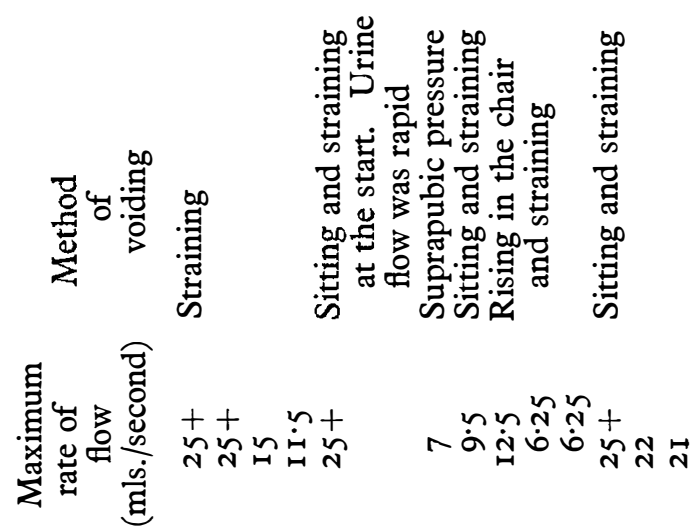

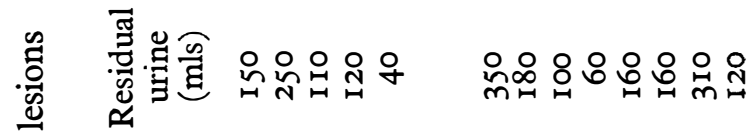

•

突

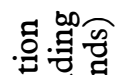

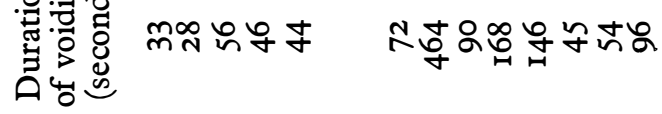

疍

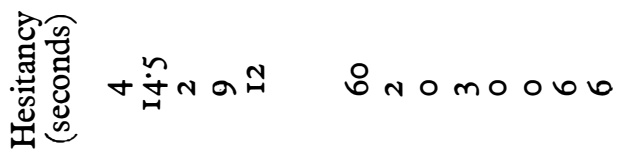

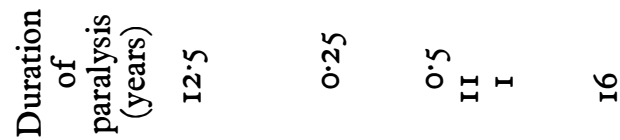

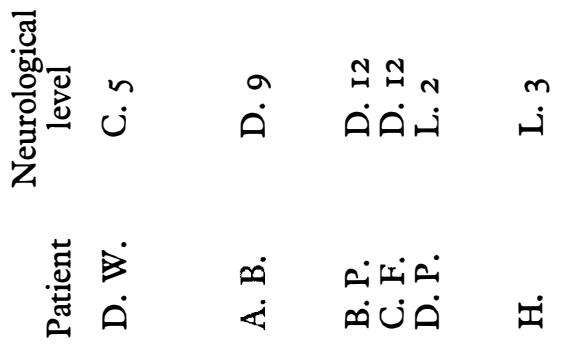




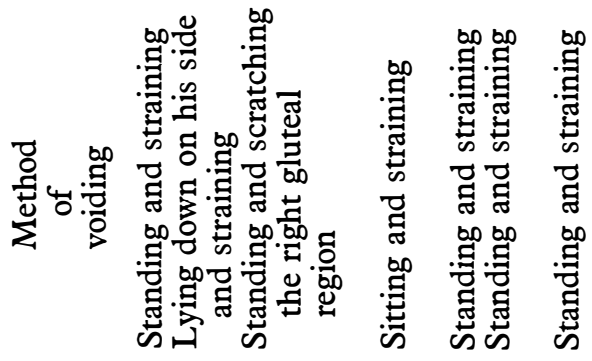

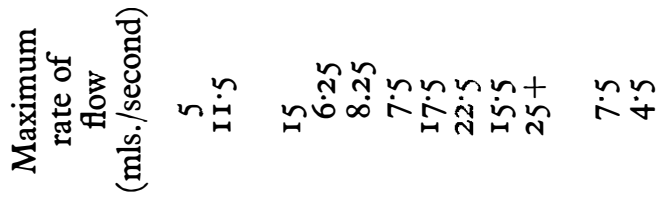

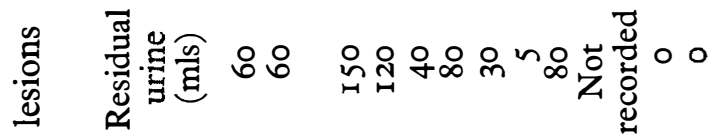

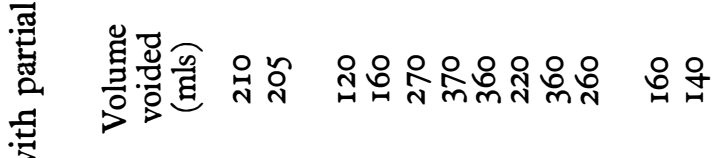

$$
\begin{aligned}
& \text { 당 }
\end{aligned}
$$

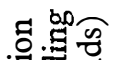

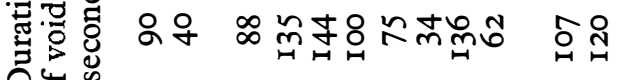

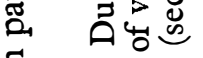

$$
\begin{aligned}
& \text { 总焉 }
\end{aligned}
$$

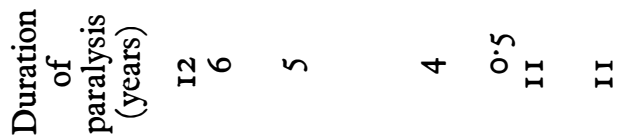

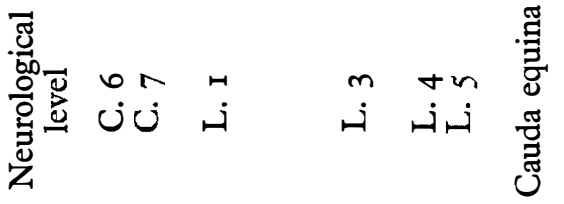

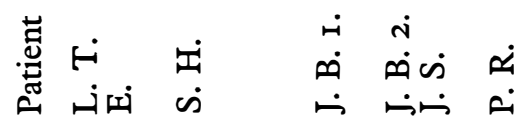




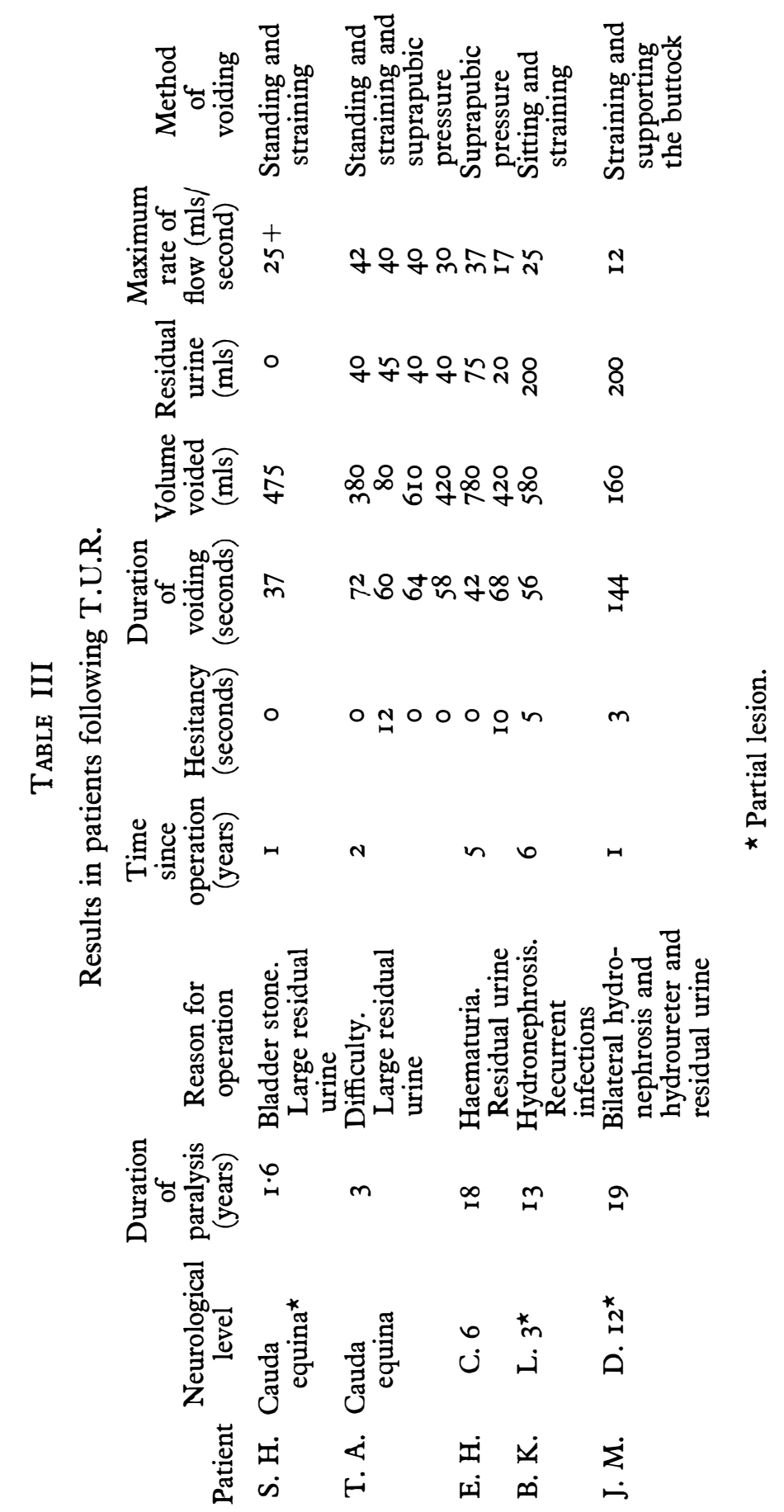


micturition patterns after spinal cord injury differed significantly from the normal whether the lesion was complete or incomplete. The period of hesitancy was variable and might be prolonged; urine commonly flowed only on abdominal straining and the flow rate was usually low. Only the patients studied following transurethral resection showed traces in any way similar to those obtained in the normal person.

\section{Discussion}

It is well known that patients may suffer many urological problems following spinal cord injury including difficult micturition, large residual urine, recurrent cystitis, pyelonephritis, hydronephrosis, stone formation and renal failure.

We have previously shown that micturition in the paraplegic patient is often associated with an unphysiological rise in bladder pressure (Smith, Cook and Prasad, 1974), and that patients with indwelling catheters have a lesser incidence of damage to the upper urinary tract than do those using condom or other urinals (Smith and Cook, I968).

The present study highlights the abnormalities of urine flow in patients after spinal cord injury whose micturition was apparently satisfactory. It emphasises again that bladder training is liable to produce an unphysiological result consistent with a diagnosis of bladder-neck obstruction in the patients with an intact spinal cord.

It is our suggestion that routine studies of urine flow patterns in patients following spinal cord injury indicate the necessity for transurethral resection of the bladder neck and external sphincter in a high percentage, if long-term urethral catheterisation is not considered desirable.

\section{SUMMARY}

Patterns of micturition in normal subjects and in patients after complete and incomplete injury of the spinal cord have been compared.

All patients showed an abnormal flow pattern, this being least obvious in those who had undergone resection of the bladder neck and external sphincter. It is suggested that the Disa type I4 F 45 mictiograph is a useful instrument in determining the need for transurethral resection following spinal cord injury.

\section{RÉSUMÉ}

On a comparé les phénomènes de miction chez des sujets normaux et chez des malades après lésion complète et incomplète de la moelle épinière. Tous les malades accusaient un écoulement normal. Ce phénomène était le moins évident chez les sujets ayant subi une resection du col de la vessie et du sphincter externe. On suggère que le mictiographe de type 'Disa I4 F 45' est un instrument utile pour déterminer la nécessité d'une resection transurétrale après une lésion de la moelle épinière.

\section{ZUSAMMENFASSUNG}

Formen der Miktion bei Normalen und Patienten mit kompletten und inkompletten traumatischen Läsionen des Rückenmarks werden verglichen. Alle Patienten zeigten 
abnormale Miktionsformen, am geringsten diejenigen, bei denen eine Resektion des Blasenhalses und des Sphinkter externus vorgenommen wurde. Der Disa Typ I4 F 45 hat sich als ein branchbares Instrument für die Indikation der transurethralen Resektion nach Rückenmarksverletzung erwiesen.

Acknowledgements. We should like to express our thanks to Mrs. S. Stevenson for her help in typing the manuscript and to the Department of Medical Illustration at Leeds (St. James's) University Hospital for the photographs.

\section{REFERENCES}

SMITH, P. H. \& Cook, J. B. (I968). Long-term urethral catheterisation after spinal cord injury. Paraplegia, 6, I I-I6.

SMIth, P. H., CoOK, J. B. \& PraSad, E. W. M. (1974). The effect of ubretid on bladder function after recent complete spinal cord injury. British fournal of Urology, 46, I87-I92. 